\title{
The archaeology of South Sudan from c. 3000 BC to AD 1500
}

\author{
David K. Kay, Samuel Lunn-Rockliffe, Matthew I.J. Davies
}

\section{Introduction}

Situated at the eastern edge of the Sahel, the western fringe of the Ethiopian highlands, and to the South of the well-known Nubian Kingdoms, present day South Sudan is well positioned to deepen our understanding of the continent's history. The region likely holds crucial archaeological information regarding important developments in African pastoralism, agriculture and metalworking for both earlier and more recent periods. A handful of expeditions undertaken by the British Institute in Eastern Africa (BIEA) from 1979-82 remain the only concerted archaeological ventures into the country (Mack and Robertshaw 1982). These expeditions revealed a wealth of remains from multiple periods and places, uncovering spatially and temporally diverse pottery styles and lithic assemblages. However, these studies raised many more questions than answers, acting more as an index of the rich archaeological heritage of the region. More recent excursions undertaken by Lane (Lane and Johnson 2009) and Davies $(2012,2014)$ contribute further to these findings, but have been geographically and temporally restricted, focusing on historic periods, including colonial encounters and the nineteenth century slave trade.

In this paper, we review current archaeological knowledge of South Sudan with particular focus on the period from $3000 \mathrm{BC}$ to $\mathrm{AD} 1500$. This date range roughly spans the period from before the rise of the Nubian kingdom of Kerma c. 2500 BC to the beginning of the Funj Sultanate, i.e. from the development of more well-known 'state level' societies to the immediate north until the beginning of concerted colonial activity (both Islamic and European). We outline the evidence from key known sites relating to this broad period, and then develop a series of questions for the future of South Sudanese archaeology.

\section{History of Research}

The earliest textual sources on present day South Sudan come from Classical Greek and Roman writers, who give accounts of several expeditions south of Meroë that attempted to ascertain why the Nile flooded and to locate its source. Most notable is the well-documented journey south of the Roman vassal state of Meroë by Emperor Nero in the first century AD (Kirwan 1982: 71-72). This expedition is reported on by both Pliny and Seneca, and while the validity behind many of the details are questionable (Kirwan 1982: 72-73), these sources are largely the sum of documentary evidence until the Islamic period. Whether the region enjoyed sustained contact with other regional polities, such as Meroë, peoples across the Red Sea, particularly the Sabeans, or even later Christian kingdoms in Ethiopia, of which Aksum was the largest, remains something of an unknown. As outlined below, existing archaeological research has little to say on such connections, but future work may be usefully undertaken to shed new light on this.

Following the Islamisation and Arabisation of the northern Sudan from the seventh century AD onwards, a relatively fluid border was maintained with the non-Islamic lands to the south. The Funj and Dar Fur Sultanates (AD 1504-1821 and c. AD 1650-1874 respectively) in particular launched regular slave raids to the south, followed by itinerant merchants (jallaba) looking to obtain ivory and ostrich feathers. This volatile situation created the impetus for population movement, religious/ethnic renegotiation and further socio-political changes amongst the peoples of the Upper Blue Nile and Bahr al-Ghazal (Lane and Johnson 2009; 
O'Fahey 1982: 75). It was Salim Qapudán and his expeditions of 1839-1842 that opened the southern White Nile to concerted external influence, resulting in a series of fortified settlements (zariba) maintained by Khartoum-based trading companies (kubaniyya). These traders, armed with guns and greater manpower, quickly undercut the sultanates by diverting the northward flow of slaves, ivory and copper and creating new commercial empires under their own aegis (Lane and Johnson 2009; O’Fahey 1982: 83-84).

The first detailed European source on what is now South Sudan are the writings of Samuel Baker, who travelled extensively in Equatoria in 1862-1865 and later became the head of a Turko-Egyptian army in order to annex the country (Baker 1895 [1874]). Baker described the regions of Rejaf and Moogé in particular as being well inhabited with numerous villages, farms and herds of cattle (Baker 1895 [1874]: 231-256). Further Turko-Egyptian expeditions followed, and in 1874 Colonel (later General) Charles Gordon arrived and began building a series of fortified stations throughout the region, of which that at Laboré has been the subject of recent archaeological assessment (Davies 2009, 2014). Gordon's successor Dr Eduard Schnitzer, aka Emin Pasha, greatly consolidated British influence in the region including the establishment of a key fort at Dufile, archaeologically investigated by Posnansky (2005; see also Stigand 1923). However, following the Mahdist revolt of 1883, Pasha and his garrison forces were forced to retreat from the region (Mounteney-Jephson 1890, Stanley 1890), facilitating the brief rule of the Mahdist state before its eventual destruction at the hands of a British army (Moorehead 1960).

Through the early $20^{\text {th }}$ century numerous ethnographers and colonial officials recorded the material and architectural cultures across southern Sudan, including Titherington (1923) who noted the 'city mounds' of the Dinka. A full account of these $20^{\text {th }}$ century material ethnographies is not possible here, but considerable new work is currently being produced on this front and offers multiple lines for future archaeological enquiry (Cormack and Leonardi in press).

The near-continual state of unrest in the region since independence in 1956 has resulted in a notable scarcity of archaeological research, with an especial dearth of publication on prehistoric sites. The earliest archaeological research was probably that carried out by Else Kleppe in then-Upper Nile Province in 1976-1977, which focussed on debbas sites associated with the Funj Sultanate in the vicinity of modern-day Malakal and Er Renk on the White Nile (Edwards 2005: 24; Kleppe 1982). Debbas are mound-sites, comprised of collapsed building material and accumulated refuse, found on low-lying ridges that stand above the floodplains, today inhabited by Dinka and Shilluk populations. Pot sherds recovered here are said by local Dinka/Shilluk to be 'Funj' and unrelated to their own past, although concrete links with the Funj Sultanate of AD 1504-1821 remain speculative (Kleppe 1982). It was not until a series of surveys conducted by the BIEA between 1976-1981 that a wider range of archaeological sites and material emerged (David et al. 1981, Mack and Robertshaw 1982, Phillipson 1981, Robertshaw and Mawson 1981). For the most part, it is these ground breaking expeditions, in conjunction with the results of more limited recent work, that this paper draws upon to create a synthetic overview of the archaeology of southern Sudan.

BIEA expeditions 1977-1981

The first survey was directed by David Phillipson (1981) between 1977-1978 and covered the southern provinces of- Bahr el Ghazal, Western Equatoria and Eastern Equatoria. Surface scatters of Late Stone Age (LSA) microliths were found here amongst rocky outcrops such as Landili Hill. Middle Stone Age (MSA) prepared-core industries were absent from this area, 
being found only around the White Nile near to Juba, whilst chipped microlith debris was more prevalent at small cave and rock shelter sites to the west, such as near Jebel Riwa, Ibu and Tsimbia. These latter assemblages were also associated with pottery sherds, and in some cases ground stone axe production, suggesting a possible 'Neolithic' industry in the far southwest . Multiple Iron Age sites were also documented, mostly consisting of small individual homesteads strung out along river valleys, with two buried iron smelting furnaces uncovered at Maridi River (Phillipson 1981: 3-4). In 1979, additional surveys in Bahr el Ghazal were spearheaded by Nicholas David (David et al. 1981) and focussed on the seasonally flooded grasslands around Wun Rok, where Titherington (1923) had first reported Dinka 'city mounds'. Twenty mounds were recorded, ranging from a few centimetres to five metres in height and 50-200 metres across. Excavation of the Dhang Rial mound is discussed in detail below. David also excavated two sites initially observed by Phillipson (1981) Jebel Tukyi in Western Equatoria (110 km northwest of Juba) and at Lokabulo in Eastern Equatoria (200 km east of Juba), both are presented in detail below.

In 1980, Peter Robertshaw undertook a further expedition, focussing on the province of Eastern Equatoria, an area of particular interest as a melting pot for Nilotic and Cushitic languages/cultural traits, and a major north-south transit route (Robertshaw and Mawson 1981: 55). This season saw the test excavation of an ash mound site at Jebel Kathangor $(300 \mathrm{~km}$ northeast of Juba), Itohom rockshelter at the foot of the Imatong Mountains (170 km southeast of Juba) and a second rockshelter in the Luluba Hills (80 km southeast of Juba), each are discussed below. Robertshaw undertook a further expedition in 1981centred on the Lakes (El Buheyrat) Province. Research was focussed east of Rumbek, where the savannah woodland and farmlands of the ironstone plateau descend into the lowland plains containing the Sudd and surrounding toich grasslands. Agar Dinka cattle camps at the interstices of these two zones are often re-occupied year on year, forming ash mounds that rise above the surrounding toich. These mounds were the main focusand a total of six were subjected to trial excavation - Jokpel, Ngeni A and B, Bekjiu, Kat and Na'am (Robertshaw and Siiriäinen 1985) - each are discussed below.

\section{Other surveys}

Aside from the BIEA expeditions, other archaeological research conducted in this period is sparse, an exception being observations made during ecological surveys in Bangangai Game Reserve in the south-west of the country (Hillman and Hillman 1984). These noted a series of undated grinding grooves in a rocky streambed, most likely used for manufacturing ground stone axes. Several iron furnaces of a 'funnel variety' and tuyères and slag were also noted (Hillman and Hillman 1984: 115-117). More recently, surveys undertaken by Paul Lane in 2007 near Rumbek to investigate traces of nineteenth slavery and ivory trading (Lane and Johnson 2009). Three principal sites were identified. Pendit on the northern edge of Rumbek consists of a sub-circular causewayed enclosure, approximately 150 metres in diameter, and is identified as a $19^{\text {th }}$ century zariba and probable base of the trader/slaver Alphonse de Malzac. Low density artefact scatters consisted of local pottery sherds (many cord-rouletted), fragmentary animal bones, glass beads and occasional fragments of imported glazed ceramics and bottle glass (Lane and Johnson 2009: 525-529). The other two sites, Meen Atol $(5.4 \mathrm{~km}$ south-south-west of Rumbek) and Lol Nhom (located $35.3 \mathrm{~km}$ further south) are further examples of zaribas (Lane and Johnson 2009: 529-532). As $19^{\text {th }}$ century sites we do not discuss these sites further in this paper but instead refer the reader to the original material.

Surveys by Davies in 2009 focussed intensively on the banks of the Nile between Juba and Nimule and concentrated on survey zones at Shukoli, Laki and Bedden (Davies 2012, 2014). 
No excavations were undertaken but survey recorded some 110 sites or clusters of archaeological features including semi-fortified villages, stone walling, field terraces, stone cairns, standing stones, furnaces/slag and scatters of ceramics. Also notable was the discovery of a major late $19^{\text {th }}$ century Turko-Egyptian garrison fortress at Laboré discussed in detail in Davies and Leonardi (2012) and Davies (2014). These finds speak to densely occupied landscapes with extensive evidence of villages and cultivation. Substantial evidence of iron working was also present, including several clear furnace bases, as well as stone cairns and standing stones potentially indicating funerary architecture. A majority of ceramics found were rouletted and similar to $20^{\text {th }}$ century examples. Finds clearly predating the last few hundred years were very rare, but several sites may be older, including the walled enclosures at a location known at Renjuk, and the complexes of terracing, walling, cairns, standing stones and iron working remains at sites recorded as A09-11, C11, F16 and Y04 (Davies 2012). Multiple rock shelters in the Shukoli survey zone produced only small numbers of undiagnostic ceramics and undifferentiated late stone age quartz lithics, while only a handful of isolated late stone age lithics were recovered from across the other survey zones. These sites offer considerable potential, however, in the absence of excavation and dating, and given that plans and photographs are presented in Davies (2012), we do not focus further on these in this article.

\section{Key excavated sites}

In what follows we offer a summary of the key excavated sites across South Sudan, describing their basic characteristics, the excavations undertaken, general finds and tentative dating. These data are summarised in Table. 1, which includes all of the known radiocarbon dates for the country. The location of each site is given on Figure. 1. In many cases the work undertaken at each site was limited and many details and analyses remain incomplete. Many of the finds remain housed at the BIEA where future analyses could be undertaken. We follow these site descriptions with some tentative discussions of chronology and key themes for future investigation.

\section{Lokabulo}

Located east of the White Nile and just north of the villages of Loryok and Irum (Fig. 1), Lokabulo rock shelter produced a long sequence evidencing occupation by a preceramic LSA hunter-gatherer population prior to $3000 \mathrm{BC}$ (see Table. 1). Quartz-tempered and combimpressed pottery appearing at roughly $2000 \mathrm{BC}$, alongside a decrease in the preponderance of lithics (quartz and some diorite flakes predominate in the lower layers, whilst a small number of microliths occur throughout the sequence). The LSA pottery include both restricted and open-mouthed vessels, pots and bowls with round bases, and whilst more varied than that found at Jebel Tukyi (see below), are reported to be generally similar to other ceramics spread throughout Eastern Equatoria. Three 'fibre-rouletted' sherds from the top of the sequence likely evidence a fleeting Iron Age presence. All fauna recovered were of wild taxa suggesting deposits pre-date livestock in this region. The partial remains of a human skeleton were excavated in Layer 3 of Trench IX-X P, although these do not seem to have been placed within a grave cut. The rock shelter seems to have been abandoned sometime near the end of the first millennium BC, with $19^{\text {th }}$ century reutilisation as a cattle byre (David et al. 1981: 11-19).

\section{Jebel Tukyi}

Jebel Tukyi rock shelter, located $1.5 \mathrm{~km}$ southwest of Lui, produced a sequence revealing a ceramic-using Late Stone Age (LSA) hunters and cattle herders, beginning in the first millennium $\mathrm{BC}$ and continuing into the first millennium $\mathrm{AD}$ (i.e. later than that at Lokabulo). After a hiatus, these werefollowed by a Later Iron Age occupation beginning several centuries ago. A radiocarbon date of AD 1380 \pm 55 associated with 'fibre-impressed' pottery (see Table. 
1) is cautiously posited as the latest possible appearance of this Iron Age tradition in the area (David et al. 1981: 25; Table. 1). The LSA pottery belongs to a quartz-tempered and combimpressed tradition similar to those of Lokabulo, though less varied in form and largely consisting of open-mouthed, hemispherical vessels with rounded bases and simple rims. Rare examples were also recovered of rocker-stamped and twisted cord-impressed sherds, whilst some were covered with an ochreous wash before the application of comb decoration. Flaked stone tools, including some microliths, were present throughout the sequence, particularly in the lower levels, though co-occurrence with iron slag in several layers suggested a degree of post-depositional admixture. Evidence of domestic cattle in these LSA layers is particularly interesting as it demonstrates an early spread of pastoralism to an area only $100 \mathrm{~km}$ north of the present-day moist lowland forest belt, and has been tentatively associated the expansion into this region of Central Sudanic language speakers (David et al. 1981: 30-31). The Iron Age pottery belongs to a rouletted tradition, utilising a variety of plaited fibre roulettes. A few examples of twisted cord and carved wooded roulette decoration were also recovered. These pots are also larger, though the only recognisable form is of vessel with a restricted mouth and slightly thickened lip (David et al. 1981: 20-31).

\section{Jebel Kathangor}

The deflated ash mound of Jebel Kathangor, covers an area of $2000 \mathrm{~m}^{2}$ and is topped by a stone cairn some $1.75 \mathrm{~m}$ high. Although the site is potentially extensive, a single test pit revealed little in the way of stratigraphy and no radiometric dates. The few lithics recovered were similar to other heterogenous LSA/Pastoral Neolithic flake/blade industries from East Africa, although notably different to the better-defined Eburran or Elmenteitan industries of Kenya (Robertshaw and Mawson 1981: 70-72; although cf. Wilshaw 2016). The pottery is more varied than the lithic assemblage, displaying a wide-ranging suite of decorative treatments, including impressions, incised cross-hatching, comb impressions, horizontal 'walked' impressions, twisted cord rouletting, and a few examples of bosses and broken lugs. Ceramics with grooved lines and horizontal 'ribbing' appear to represent a variant of the Turkwel pottery from the region west of Lake Turkana, which is poorly dated to between approximately AD 450 and AD 1100 (Robertshaw and Mawson 1981: 81). It is currently very difficult to place this assemblage within established sequences. Though the faunal assemblage is small, cattle are clearly represented, as are Thomson's gazelle (Eudorcas thomsonii) and waterbuck (Kobus ellipsiprymnus).

\section{Dhang Rial}

Dhang Rial mound spans 175 metres with a height of $2.7 \mathrm{~m}$ above the plain. Excavation revealed initial occupation predating the mound and, though there is no secure dating for this phase, the distinctive comb-impressed pottery is reported to be LSA in origin, albeit stylistically distinct from Lokabulo or Jebel Tukyi (David et al. 1981: 31-33). The formation of the mound as a settled site begins at around AD 500, prior to the radiocarbon date of $\mathrm{AD}$ $765 \pm 85$ recovered from Layer 2 of Trench II (see Table 1.). Layers 2 and 3 in Trench I also contained a series of human burials which date to this Iron Age phase. Layer 2 held at least fifteen adults and in Layer 3 five adults and one child were unearthed with iron artefacts including bracelets and neck torcs (see below for discussion). This phase is characterised by ceramic vessels decorated with bands of twisted cord rouletting below the lip and tempered with quartz andgrog (David et al. 1981: 40, 49). Clay figurines also point to husbandry of nonhumped domestic cattle,supported by zooarchaeological evidence of cattle from the excavations . Cattle remains sit alongside wild taxa including fish. A third phase, beginning around $\mathrm{AD} 14^{\text {th }}-15^{\text {th }}$ based on historical grounds and post-dating the Layer $1 \mathrm{~b}$ radiocarbon date of AD $1220 \pm 75$ (see Table. 1), were interpreted as a transition to a Later Iron Age and are 
marked by the introduction of humped cattle figurines, a cessation in shell bead manufacture and an increased incidence of cord-rouletted pottery reminiscent of modern-day Dinka Tuich ceramics (David et al. 1981: 49-50).

\section{Jebel Kachinga}

Surveys at Jebel Kachinga revealed two sites - a small rock shelter at the eastern end of the hill, and an open site some $200 \mathrm{~m}$ further west that only yielded surface collections. Test excavations at the rock shelter returned a large quartz microlithic assemblage, plus an ochrestained quartzite rubber/upper grinding stone. Ceramic sherds were from jars or pots with both straight and everted rims, decorated with oblique incisions or comb impressions below the rim. Domestic cattle are evidenced by a few teeth. The ceramic assemblage from across these two sites is reportedly distinct from other archaeological collections in Eastern Equatoria, though similarities are noted with that of the modern-day local Toposa population, and also the Lanet/Sirikwa tradition of western/central Kenya (Robertshaw and Mawson 1981: 76-78).

\section{Itohom}

Excavations at Itohom rock shelter, located $40 \mathrm{~km}$ from Torit at the foot of the Imatong Mountains, recovered over 20,000 pieces of worked stone, mostly informal quartz flakes, with some scrapers and small backed tools together with larger volcanic rock tools and grindstones. The lithics display little stratigraphic variation, but the pottery is distinctive of two distinct traditions, and thus possibly separate occupations. The first comprises small undated LSA pots with closed mouths and simple rims, and comb impressions applied in horizontal bands. The second seem directly related to contemporary Lango pots, mostly jars with everted rims and bands of rouletting. Although some evidence of domesticated cattle and ovicaprids was recovered, they were few in number and may relate only to the recent occupation. A burial in the upper sequence contained the remains of three adults which given the inclusion of a horse tibia may be of quite recent date (Robertshaw and Mawson 1981: 60-64).

\section{Lulubo}

Located between Juba and Torit, Lulubo rock shelter displayed a similar sequence to that of Itohom, with the uppermost layers returning twisted cord-rouletted ceramics akin to modern Luluba wares, and the lower levels containing sherds of comb-impressed pots with restricted mouths alongside informal quartz tools (Robertshaw and Mawson 1981: 66-69). A 'pavement' of crushed potsherds, including some with knotted roulettes - identified by locals as either a sorghum-threshing floor or hut doorway - was also found just below the surface in a level. The layer included twisted cord- and knotted-rouletted ceramics, indicating a distinction from the overlying Luluba-like sherds. Radiocarbon dates suggest lithic manufacture ceased around AD 1000, and definitely before AD 1650 (see Table. 1). Three pieces of iron slag from the level dated to c. AD 1000 are held as an approximate indicator for the early spread of iron working to the region, although these may be intrusive (Robertshaw and Mawson 1981: 68, 69-70).

\section{Jokpel}

Of the several ash mounds encountered by the 1981 expedition, six were subjected to trial excavation (Robertshaw and Siiriäinen 1985: 89-92). Jokpel is situated on the boundary between the ironstone and the toich. Excavations identified four phases. Phase I was characterised by fine undecorated bowls, along with fired clay 'balls' and figurines that may represent hump-less cattle. Cattle are also found amongst the faunal remains, alongside wild ungulates and fish andoccasional flaked quartz artefacts. Phase II is marked by thicker, coarser 
pottery decorated with woven-mat impressions. The fauna is similar to Phase I, with the addition of caprines. The lithic assemblage, whilst small, is also comparable. Phase III is essentially a continuation of Phase II, distinguished only by the appearance of burnt clay floors containing post-holes. This mayrepresent spatial variation rather than explicit cultural change. Lastly, Phase IV consists of the upper ashy layers of the moundreflecting its more recent use as a cattle camp. Pottery is rouletted, including twisted and knotted cords, with 'plaited grass' roulettes being indistinguishable from modern Dinka examples. Although no radiocarbon dates were obtained from the site, comparison with woven-mat impressed pottery at Bekjiu (see below) suggests Phases II-III date to the late first millennium AD, whilst Phase IV belongs to the last two-three centuries (Robertshaw and Siiriäinen 1985: 92-104).

\section{Ngeni $A$ and $B$}

Located in the more open grassland at Ngeni, Ngeni A and B revealed a similar sequence to that of Jokpel. Ngeni A returned fragments of burnt clay floors and rubble. The majority of pottery sherds were woven-mat impressed, though one was rocker stamped in a manner comparable to Kat (see below). Excavation at Ngeni B also encountered one hardened clay floor. Most of the pottery was again comparable to that from Jokpel and Ngeni A, five body sherds had horizontal grooving reminiscent of Turkwel ceramics from north-west Kenya and similar to those at Jebel Kathangor. Fired clay balls and 'figurines' were also recovered from both sites, but there is no evidence of iron working. Both sites are also characterised by a faunal assemblage comprising a range of wild game and fish alongside cattle and caprines. No radiocarbon samples were forthcoming, but the woven-mat impressed ceramics suggest occupation during the latter part of the first millennium AD (Robertshaw and Siiriäinen 1985: 104-112).

\section{Bekjiu, Kat and Na'am}

These three sites are all also ash mounds, though located some distance west of Jokpel and Ngeni. Bekjiu is situated on the ironstone rim $1 \mathrm{~km}$ west of the toich of the Na'am river valley. Much of the material seemed to have accumulated within the latter half of first millennium AD with particularly rapid deposition between the $7^{\text {th }}$ and $10^{\text {th }}$ centuries. Notably, the skeleton of an adult male was found in a burial pit about two metres below the present surface, though no grave goods were found (Robertshaw and Siiriäinen 1985: 112-115). Flaked quartz artefacts numbered only three in total, but pottery was more abundant, characterised by restricted mouth bowls with woven-mat impressions. Lower stratigraphic levels revealed several sherds decorated with a zigzag motif, perhaps indicative of an earlier phase of occupation. Pottery disks and small clay 'balls' akin to those at Jokpel and Ngeni were also found in the lower half of the deposits. Some carved roulette decorated sherds were found closer to the surface, as well as traces of pole-and-daga structures.Radiocarbon dates suggest that these structures were built just before AD 1000 (Robertshaw and Siiriäinen 1985: 113-118; see Table. 1). Occasional pieces of slag and iron were found throughout the sequence indicating knowledge of iron working, though the evidence is not abundant. The faunal assemblage varies little throughout, demonstrating a mixed economy of herded cattle and caprines, together with the hunting of wild species, including marine taxa such as fish, crocodiles and terrapins. Although no botanical remnants of domestic crops were recovered, the presence of several grindstones suggests that agriculture may have been practised (Robertshaw and Siiriäinen 1985: 119-126).

The site of Kat is located $5 \mathrm{~km}$ north of Bekjiu, at the transition from the toich to more wooded grasslands, and was still used as a wet season camp by Agar Dinka. A single test pit revealed a layered stratigraphy of ashy/sandy loams. Cattle bones were present throughout, alongside 
wild ungulates and terrapins. A single pearl millet seed was also found in the upper occupation layers. Radiocarbon dates of the upper ashy layers suggest they relate to recent use of the site as a cattle camp, as also evidenced by the numerous post-holes and 'plaited grass' roulette decorated potsherds. The lowest layer, however, is characterised by pottery sherds with a zigzag design akin to that of Bekjiu. Thus, whilst there is no radiocarbon date this layer presumably predates the later first millennium AD (Robertshaw and Siiriäinen 1985: 126-133).

Similar to Kat is the site of Na'am located in the open toich grassland some $4 \mathrm{~km}$ west of Bekjiu. Though some $2 \mathrm{~m}$ high, most of the mound seems to have accumulated through its recent use as a dry season cattle camp. Most of the decorated pottery consists of 'plaited grass' rouletted sherds, whilst some woven-mat impressed sherds from the bottom of the sequence also showed signs of 'rolled' water abrasion, suggesting the site was regularly flooded. Fragments of iron were also found in the upper layers, alongside an off-white glass bead, an ostrich eggshell bead, a shell pendant, and fragments of four clay figurines. The zooarchaeological remains included cattle and caprines, alongside wild ungulates, birds, terrapin and fish (Robertshaw and Siiriäinen 1985: 133-138). Again, the archaeology here appears to have accumulated through its more recent use as a dry season cattle camp by the Dinka Agar, most likely due to their practice of collecting and burning dung on-site as a form of pesticide fumigation for the cattle.

\section{A tentative chronology for the archaeology of South Sudan}

Despite the fact that the data presented above are highly partial, the past 5000 years in South Sudan have been anything but culturally homogenous, with temporally and spatially diverse archaeological material pointing towards dynamic landscapes and intriguing narratives of socioeconomic change and migration. In general, the data suggests that large parts of southern South Sudan were inhabited by stone tool using hunter-gatherers from at least $3000 \mathrm{BC}$, though direct evidence of earlier occupation remains lacking. This date of $3000 \mathrm{BC}$ comes from the pre-ceramic phase in the lower levels of Lokabulo and is followed by levels characterised by comb-impressed pottery that became prevalent (albeit with a high degree of variation) across what used to be Eastern Equatoria by 2000 BC. The spread of these ceramic types across the region is evidenced in the lower levels of Lulubo and Itohom, and possibly at Kat and Bekjiu and have been tentatively referred to as the Lokabulo tradition (Robertshaw and Mawson 1981: 80). However, given the equivocal nature of dating from across the region, there appears to be a large degree of temporal and spatial variation amongst these ceramics spanning the period from $2000 \mathrm{BC}$ to the second millennium AD. Indeed, whilst the earliest dates from Lokabulo suggest these comb-impressed LSA ceramics were in use by the second millennium BC, dates from Kat and Bekjiu are much younger - at AD 500 - and dates from Lulubo and Itohom are younger still - coming from the second millennium AD. The LSA layers at Jebel Tukyi returned markedly distinct 'comb punctate' ceramics dating to the late first millennium BC, suggesting the presence of at least two LSA ceramic traditions during this period. Moreover, while the comb-impressed LSA layers at Lokabulo, Itohom and Lulubo are associated with wild fauna ${ }^{1}$, the LSA layers at Jebel Tukyi (with comb punctate ceramics), and Kat and Bekjiu (with comb impressed ceramics), include domestic cattle alongside wild fauna, suggesting a mixed economy in the first millennium $\mathrm{BC}$ and first millennium $\mathrm{AD}$.

\footnotetext{
${ }^{1}$ There is limited evidence of domesticates in LSA levels at Itohom, although this may be intrusive from later levels (Robertshaw and Mawson 1981: 65).
} 
A mix of both wild and domestic fauna is also observed at Jebel Kathangor and Ngeni B, as well as distinct ceramic styles characterised by horizontal incisions that have been linked with the Turkwel tradition of western Turkana, which is dated to between the mid first and second millennium AD (Robertshaw and Mawson 1981; Robertshaw and Siiriäinen 1985). The distinct cultural pattern at Jebel Kathangor could be seen as one possible archaeological manifestation of a Later Stone Age to Iron Age transition. In short, the limited data available suggest a complex geography of lithic-using populations, representing a widespread hunting and gathering tradition spanning the period $2000 \mathrm{BC}$ to AD 1000, but with at least three ceramic forms: the Lokabulo tradition, Jebel Tukyi and Jebel Kathangor, with the former having origins in the first and second millennia BC respectively and the latter originating in the first millennium AD.

The appearance of twisted cord rouletted-pottery and animal husbandry from Dhang Rial suggests an early appearance of 'Iron Age' populations in northern South Sudan around AD 500 (David et al. 1981: 49). Further south, the upper levels at Itohom and Lulubo also evidence rouletted pottery, with a date of AD 1750 \pm 60 (calibrated to AD 1640-1660) from Lulubo offering a rough approximation for the introduction of iron working to the region (although this could have been earlier if the iron slag dating from AD $865 \pm 115$ is not intrusive). The carved wooden roulette-decorated ceramics at Itohom is elsewhere argued to not have reached eastern Africa before AD 1500 (David and Vidal 1977; Robertshaw and Mawson 1981: 80). The picture gleaned here is one of an Iron Age tradition emerging across South Sudan, starting in the second half of the first millennium $\mathrm{AD}$ and continuing to expand with increasing density over the next 1000 years, as indicated by a number of dates coming from the second half the second millennium AD (see Table 1). This tradition consisted of communities following a mixed livelihood of herding, hunting and fishing, and possibly also cultivating sorghum and other crops, although direct evidence for these is yet to be uncovered ${ }^{2}$. In the former Lakes Province this tradition disappears in the early second millennium AD and is later replaced by that of the Dinka Agar and Atuot. The continuance of pre-Dinka woven mat-impressed pottery in the woodlands to the south into the last few centuries (as at Jebel Tukyi), however, suggests that some Lakes Province populations may have relocated from their former savannah grasslands. Meanwhile, the continuity in cord rouletted-pottery from later Iron Age to more modern levels at Dhang Rial in the north is interpreted as evidence not of population replacement, but a gradual cultural transformation associated with the spread of humped cattle, and eventually ending in the present-day Dinka Tuich (Robertshaw and Siiriäinen 1985: 146148). Ultimately, then, the spread of domesticates, Iron Age ceramics and metallurgy are likely to have been spatially and temporally diverse, and based on current observations it is probable that there was an extensive continuation of part hunting-foraging and lithic-using lifeways well into the second millennium AD. Given this complex mosaic of interaction and movement amongst people practising diverse life-ways, the broader chronology and archaeological patterns presented here will no doubt require substantial reconsideration as and when research continues within the region.

\section{Contribution to key themes in the archaeology of the region}

\section{Food production and the southward spread of pastoralism}

\footnotetext{
${ }^{2}$ Except for a single pearl millet seed found in Layer 3 at Kat (Robertshaw and Siiriäinen 1985: 131).
} 
Despite the dearth of substantial archaeological exploration to date, South Sudan has great potential for further research to understand the spread of food production (particularly pastoralism) from northern Africa and the Nile Valley through to more southerly regions. Indeed, being located between the highlands of Ethiopia and the forested Congo Basin, the region's geographic role as a 'corridor' seems to extend to even earlier periods. Lokabulo ceramic types have certain decorative characteristics (comb impressions, walked punctates and rocked zigzags) that have been loosely linked to the Kansyore tradition around Lake Victoria, though further analysis is clearly needed as differences are also evident (Robertshaw 1982: 9293). The link with Kansyore is nevertheless intriguing, although whilst (following Sutton's (1977) questionable 'Aqualithic' theory) it may be hypothesised that the Nile Valley acted as a corridor for southwards moving hunter-fishers in the third millennium BC, there is remarkably little data on which to base this theory either in South Sudan or northern Uganda (Oliver 1982; Robertshaw 1982: 94). The linguistic affiliations of this tradition are also much debated, with Southern Cushitic, Central Sudanic and even linguistic isolates ${ }^{3}$ all remaining possibilities (David 1982; Ehret 1982; Robertshaw 1982: 95-97). Ceramics characterised by decorative horizontal incisions (most clearly observed at Jebel Kathangor) have likewise been tentatively linked with the Turkwel tradition of western Turkana and north-eastern Uganda. This has been dated to c. AD 450-1100 and explicitly linked to the spread of early Eastern Nilotic speakers, though again this interpretation must be treated with care due to differences between the respective assemblages (David 1982; Robertshaw 1982: 94-98).

Twisted cord rouletted-pottery found in association with iron working at Jebel Kachinga represents a much later tradition in the former province of Eastern Equatoria. Similar pottery is still in use by nearby Toposa communities, and is potentially comparable to the Lanet/Sirikwa tradition of the Western Highlands and central Rift Valley in Kenya, dated to the mid-second millennium AD (Posnansky 1967; Robertshaw 1982: 95), and consequently may be related to later migrations of Eastern/Southern Nilotes (Ehret 1982; Robertshaw 1982: 98). Osteological analysis of the burials from Dhang Rial has also concluded that those interred were of a typically 'Nilotic' build (tall and lean), though the lack of dental evulsion (a common pan-Nilotic practice) somewhat counteracts this ascription. The subsequent introduction of humped 'Sanga' cattle, however, is explicitly linked by the excavators to the local spread of (western) Nilotic cultural traits (David et al. 1981: 48-50). Several sites, notably Kat and Na'am, can also seemingly be linked to the historic pastoralist populations of South Sudan, especially the Dinka, and such sites thus offer a unique opportunity to explore the deeper history and heritage of contemporary populations.

In short, several ceramic types found in the region may be linked to the spread of food producing and pastoralist communities southwards into Eastern Africa, but as yet these associations require considerably more research before any clear pattern can be discerned. There are thus several questions to be addressed here. One, the timing and geographic extension of agri-pastoral groups/practices into South Sudan (presumably from the north) and their subsequent movement into other regions to the south and east. Two, the development over time of agricultural lifeways within South Sudan itself, and particularly the long history of settlement and landscape use that leads from the first herders to contemporary/ethnographically recorded groups such as the Nuer and Dinka. Three, the relation of principally hunter-gatherer communities and lifeways to this historical trajectory (i.e. was there population replacement,

\footnotetext{
${ }^{3}$ Perhaps distantly related to Hadza and other language groups previously categorised as Khoisan.
} 
assimilation, acculturation/uptake of new technologies, or a combination thereof?) should also be assessed through controlled excavation of archaeological sites throughout the region.

\section{Metal work and Funerary archaeology}

The spread of metallurgy across South Sudan is currently very poorly understood, and in most instances has been rather simplistically equated with the introduction of domesticated cattle, such as at Bekjiu and Kat, although evidence from Jebel Tukyi suggests that the former followed the latter, with lithic-using LSA communities herding cattle alongside hunting and foraging from as early as the first millennium BC (David et al. 1981: 30-31). Early instances of iron artefacts found alongside the coterminous introduction of animal husbandry come from Dhang Rial after AD 500, although there is no evidence of smelting in this region, possibly due to a lack of locally available raw materials (David et al. 1981: 44). Examples of smelting can, however, be observed elsewhere, including the furnaces at Maridi River (Phillipson 1981: 34) and fragments of slag at Itohom, Lukabulo, Bekjiu and Kat. Such examples clearly point towards technologies and knowledge systems associated with metal smelting, although a more in-depth comparison of technologies and of the social context of regional metal working is still required. Given the wide variety of smelting/smithing technologies known from ethnographic accounts, it would again be profitable to investigate the historical diversity of metalworking within South Sudan on its own terms, though always with an eye to possible connections elsewhere, perhaps down the Nile Valley or via contact with the Ethiopian highlands to the East. Although this paper only covers the period up until AD 1500, historical/archaeological records after this date certainly point to iron's centrality in regional exchange networks as well as endogenous cultural practices, which likely stems from a similar importance somewhat earlier in time.

There are numerous reports of historic and contemporary funerary practices across South Sudan, for instance as observed by Philipson (1981: 6) and Davies (2014: 171). In this paper we have noted several instances of the archaeological recovery of human skeletal material, such as the burial of three adults at Itohom or the adult male at Bekjiu, but substantial interpretations have not yet been advanced due to the sheer lack of available data (in contrast to the rich content of the ethnographic record regards this subject). That said, the numerous burials and associated artefacts discovered in the Iron Age Layers 2 and 3 of Trench I at Dhang Rial are highly intriguing (David et al. 1981). The skeletal remains in Layer 2 comprised at least fifteen adults, and those in Layer 3 five adults. Those in Layer 2 were buried all together on ground then earthed over rather than in actual grave cuts, and the excavators thus suggest that these people died in a single event, perhaps being killed during an inter-village raid. Conversely, the underlying remains of five adults and a child in Layer 3 seem to have been buried in formal graves, and include the vast majority of iron artefacts (bracelets, leg ornaments and neck torcs) and shell beads (strung into necklaces) found across the site (David et al. 1981: 33-34, 44-49). Numerous stone cairns and other funerary monuments (such as standing stones) also abound across the region but are yet to be investigated archaeologically (Davies 2013). Clearly the country presents considerable potential to develop a funerary archaeology and to tie these further into regional sequences. In such cases there is much work to be done on tracing not just possible connections with contemporary/historic populations and practices, but also in attempting to construct a more cohesive set of understandings about how past communities lived and died, e.g. what was seen as a 'proper' death/burial and for whom, how this was connected with other facets of cultural practice, and how often distinctive burial norms were contravened/modified in different times and places.

\section{Concluding Remarks and Future Considerations}


From the above discussion, it is evident that archaeological work across South Sudan has been extremely minimal. This scarcity can be attributed to a huge array of factors that have stifled more consistent forms of research, the most obvious of which are the pressing issues associated with political volatility and social unrest. Nevertheless, a concerted drive towards further research in South Sudan could provide a significant opportunity to explore a set of broader themes in African prehistory and archaeology, in addition to vastly expanding our understanding of the history of the specific region itself. Indeed, given South Sudan's geographical positioning, an abundance of possible questions can be addressed covering a vast time span, from the migration of humans out of Africa, to the spread of Holocene huntergatherers, pastoralism and food production, to the expansion of metallurgy and the intensification of agricultural livelihoods, or the complex relationships and dramatic shift in power dynamics that emerged with various colonial encounters.

Thus, whilst insightful in its own right, the existing research discussed in this paper is in some ways presented as an index to a set of rich narratives waiting to be explored through more substantial archaeological investigations. However, in considering such future research in the region, as Davies (2014) has highlighted, there is a broader opportunity for scholars to take a conscious step towards exploring African pasts within a more radical post-colonial framework. This is to say that future work should foreground African-derived histories and produce research paradigms which more explicitly address local narratives, identities and concerns as understood by indigenous communities. While exploring the archaeology of South Sudan as it relates to or parallels the Nubian Kingdoms may be a useful start, or indeed its place in sub-continental histories of migration and pastoral development, there is a pressing need to develop an archaeology of South Sudan on its own terms. Such an approach should thus resist temptations to reproduce Western narratives such as those of cultural evolution that are preoccupied with the unpacking the development and expansion of simple communities into complex societies in a relatively linear fashion, or the overt focus on 'firsts' - such as the first food producers and first metal workers. Rather, future research in South Sudan can, and should, look towards constructing a far more multivocal view of the past, driven by African agendas and perspectives and possessed not just by outside researchers, but by local scholars and communities whose livelihoods and identities are entangled with regional histories. It is in this sense that the diversity hinted at in the excavations discussed above could act as a valuable starting point for the creation of more localised histories that speak to the complexity of the past as much as to the more well-known heterogeneity of the ethnographic present. Whilst the history of South Sudan post-AD 1500 is generally better known, most often through the lens of colonial encounter, it is precisely this 'middle' period between the deep past and more recent events that has thus far been neglected within the country, and which archaeologists are now best placed to rectify. While we thus here produce a fairly standard chronological and thematic narrative, we offer this as a reminder of the country's great archaeological potential and as an attempt to inspire future interest in the absence of more recent original research.

References:

Baker, S. (1895 [1874]) Ismailia: A narrative of the expedition to central Africa for the suppression of the slave trade. London: Macmillan

Cormack and Cherry in press - full details to follow soon 
David, N. (1982) 'The BIEA Southern Sudan Expedition of 1979: the interpretation of the archaeological data' in J. Mack and P. Robertshaw (eds.) Culture History in the Southern Sudan: Archaeology, Linguistics and Ethnohistory. Nairobi: British Institute in Eastern Africa, pp. 49-58

David, N. and Vidal, P. (1977) 'The Nana-Modé village site and the prehistory of the Ubangian-speaking peoples' West African Journal of Archaeology, 7: 17-56

David, N. et al. (1981) 'Excavations in the Southern Sudan, 1979' Azania: Archaeological Research in Africa, 16 (1): 7-54

Davies, M. (2009) Memorandum: Archaeological and Historical Sites impact assessment BAHR EL-JEBEL HYDROPOWER PROJECT. Sydney: SMEC International Pty Ltd

- (2012) 'BIEA Archaeological Surveys in the Juba-Nimule Nile Region of South Sudan 2009’ Nyame Akuma, 78: 23-40

- Davies, M.I., 2013. Stone cairns across eastern Africa: a critical review. Azania: Archaeological Research in Africa, 48: 218-240.

- (2014) 'Archaeology in South Sudan past and present: Gordon's fort at Laboré and other sites of interest' Sudan \& Nubia, 18: 165-176

Edwards, D.N. (2005) 'Research themes in the Archaeology and Cultural Heritage of the southern Sudan' in Protecting and Conserving the Cultural Heritage of South Sudan: Defining Priorities for Action, Nairobi: British Institute in Eastern Africa, pp. 24-28

Ehret, C. (1982) 'Population movement and culture contact in the Southern Sudan, c. 3000 BC to AD 1000: a preliminary linguistic overview' in J. Mack and P. Robertshaw (eds.) Culture History in the Southern Sudan: Archaeology, Linguistics and Ethnohistory. Nairobi: British Institute in Eastern Africa, pp. 19-48

Evans-Pritchard, E.E. (1940) The Nuer: A Description of the Modes of Livelihood and Political Institutions of a Nilotic People. Oxford: Clarendon Press

Kirwan, L.P. (1982) 'Greek and Roman expeditions to the Southern Sudan' in J. Mack and P. Robertshaw (eds.) Culture History in the Southern Sudan: Archaeology, Linguistics and Ethnohistory. Nairobi: British Institute in Eastern Africa, pp. 71-74

Lane, P. and Johnson, D. (2009) 'The Archaeology and History of Slavery in South Sudan in the Nineteenth Century' in A.C.S. Peacock (ed.) The Frontiers of the Ottoman World, Oxford: Oxford University Press pp. 509-537

Mack, J. and Robertshaw, P. (1982) Culture History in the Southern Sudan: Archaeology, Linguistics and Ethnohistory. Nairobi: British Institute in Eastern Africa

Moorehead, A. (1960) The White Nile. London: Hamish Hamilton 
Mounteney-Jephson, A.J. (1890) Emin Pasha and the rebellion at the equator: A story of nine months experiences in the last of the Soudan provinces. London: Sampson Low

O'Fahey, R.S. (1982) 'Fūr and Fartìt: the history of a frontier' in J. Mack and P. Robertshaw (eds.) Culture History in the Southern Sudan: Archaeology, Linguistics and Ethnohistory. Nairobi: British Institute in Eastern Africa, pp. 75-88

Oliver, R. (1982) 'Reflections on the British Institute's expeditions to the Southern Sudan, 1977-81' in J. Mack and P. Robertshaw (eds.) Culture History in the Southern Sudan: Archaeology, Linguistics and Ethnohistory. Nairobi: British Institute in Eastern Africa, pp. $165-172$

Phillipson, D. (1981) 'A preliminary archaeological reconnaissance of the Southern Sudan, 1977-8' Azania: Archaeological Research in Africa, 16 (1): 1-6

Posnansky, M. (1967) 'Excavations at Lanet, Kenya, 1957' Azania: Archaeological Research in Africa, 2: 89-114

- (2005) 'The Madi, Displacement and Resurrection of an African Population: The Dufile Research Project, Uganda 2005-2006’ African Diaspora Archaeology Newsletter, 8 (4): Article 9

Robertshaw, P. (1982) 'Eastern Equatoria in the context of later eastern African prehistory' in J. Mack and P. Robertshaw (eds.) Culture History in the Southern Sudan: Archaeology, Linguistics and Ethnohistory. Nairobi: British Institute in Eastern Africa, pp. 89-100

Robertshaw, P.T. and Mawson, A. (1981) 'Excavations in Eastern Equatoria, Southern Sudan 1980’ Azania: Archaeological Research in Africa, 16 (1): 55-95

Robertshaw, P.T. and Siiriäinen, A. (1985) 'Excavations in Lakes Province, Southern Sudan' Azania: Archaeological Research in Africa, 20 (1): 89-161

Rolandsen, O.H. and Daly, M.W. (2016) A history of South Sudan: From slavery to independence. Cambridge: Cambridge University Press

Stanley, H.M. (1890) In Darkest Africa or the Quest, Rescue and Retreat of Emin, Governor of Equatoria. London: Sampson Low

Stigand, C.H. (1923) Equatoria: The Lado Enclave. London: Constable \& Co.

Sutton, J.E.G. (1977) 'The African aqualithic' Antiquity, 51 (201): 25-34

Titherington, G.W. (1923) "“City” mounds in the Bahr el Ghazal Province' Sudan Notes and Records, 6: 111-112

Wilshaw, A. (2016) 'The Current Status of the Kenya Capsian' African Archaeological Review, 33: 13-27 